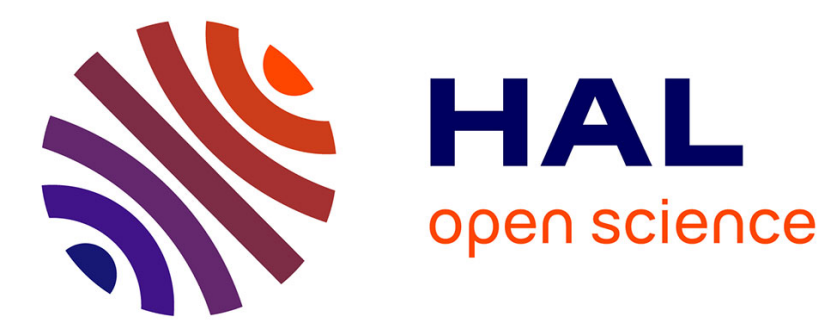

\title{
Electrochemical Formation of Germanene: pH 4.5
}

\author{
M. A. Ledina, N. Bui, X. Liang, Y-G. Kim, J. Jung, B. Perdue, C. Tsang, J.
}

Drnec, F. Carla, M. P. Soriaga, et al.

\section{To cite this version:}

M. A. Ledina, N. Bui, X. Liang, Y-G. Kim, J. Jung, et al.. Electrochemical Formation of Germanene: pH 4.5. Journal of The Electrochemical Society, 2017, 164 (7), pp.D469-D477. 10.1149/2.1221707jes . hal-02975940

\section{HAL Id: hal-02975940 \\ https://hal.science/hal-02975940}

Submitted on 23 Oct 2020

HAL is a multi-disciplinary open access archive for the deposit and dissemination of scientific research documents, whether they are published or not. The documents may come from teaching and research institutions in France or abroad, or from public or private research centers.
L'archive ouverte pluridisciplinaire HAL, est destinée au dépôt et à la diffusion de documents scientifiques de niveau recherche, publiés ou non, émanant des établissements d'enseignement et de recherche français ou étrangers, des laboratoires publics ou privés. 


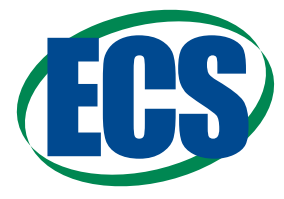

\title{
Electrochemical Formation of Germanene: pH 4.5
}

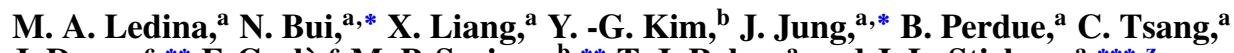 \\ J. Drnec, ${ }^{\mathrm{c}, * *}$ F. Carlà, ${ }^{c}$ M. P. Soriaga, ${ }^{\mathrm{b}, * *}$ T. J. Reber, ${ }^{\mathrm{a}}$ and J. L. Stickney ${ }^{\mathrm{a}, * * *, \mathrm{z}}$ \\ ${ }^{a}$ Department of Chemistry, The University of Georgia, Athens, Georgia 30602, USA \\ ${ }^{b}$ Joint Center for Artificial Photosynthesis, California Institute of Technology, Pasadena, California 91125, USA \\ ${ }^{c}$ ESRF, 38000 Grenoble, France
}

\begin{abstract}
Germanene is a single layer allotrope of $\mathrm{Ge}$, with a honeycomb structure similar to graphene. This report concerns the electrochemical formation of germanene in a $\mathrm{pH} 4.5$ solution. The studies were performed using in situ Electrochemical Scanning Tunneling Microscopy (EC-STM), voltammetry, coulometry, surface X-ray diffraction (SXRD) and Raman spectroscopy to study germanene electrodeposition on $\mathrm{Au}(111)$ terraces. The deposition of Ge is kinetically slow and stops after $2-3$ monolayers. EC-STM revealed a honeycomb $(\mathrm{HC})$ structure with a rhombic unit cell, $0.44 \pm 0.02 \mathrm{~nm}$ on a side, very close to that predicted for germanene in the literature. Ideally the $\mathrm{HC}$ structure is a continuous sheet, with six Ge atoms around each hole. However, only small domains, surrounded by defects, of this structure were observed in this study. The small coherence length and multiple rotations domains made direct observation with surface X-ray diffraction difficult. Raman spectroscopy was used to investigate the multi-layer Ge deposits. A peak near $290 \mathrm{~cm}^{-1}$, predicted to correspond to germanene, was observed on one particular area of the sample, while the rest resembled amorphous germanium. Electrochemical studies of germanene showed limited stability when exposed to oxygen.

(C) The Author(s) 2017. Published by ECS. This is an open access article distributed under the terms of the Creative Commons Attribution Non-Commercial No Derivatives 4.0 License (CC BY-NC-ND, http://creativecommons.org/licenses/by-nc-nd/4.0/), which permits non-commercial reuse, distribution, and reproduction in any medium, provided the original work is not changed in any way and is properly cited. For permission for commercial reuse, please email: oa@electrochem.org. [DOI: 10.1149/2.1221707jes] All rights reserved.

(cc) BY-NC-ND
\end{abstract}

Manuscript submitted March 9, 2017; revised manuscript received May 8, 2017. Published May 27, 2017. This was Paper 1313 presented at the Chicago, Illinois, Meeting of the Society, May 24-28, 2015.

Two dimensional (2D) inorganic materials have unique properties that make them attractive for integration into the nanoelectronics industry. ${ }^{1-3}$ Ever since the discovery of graphene (a single HC layer of $\mathrm{sp}^{2}$ carbon atoms), studies of its properties (high intrinsic mobility, large specific area, electrical conductivity, etc. ${ }^{4}$ ) have indicated tremendous potential for numerous applications, including: nanoelectronics, sensors, batteries, supercapacitors, field-effect transistors, and transparent conductive electrodes. ${ }^{5-7}$ Its study has also stimulated researchers into other 2D materials, such as Ge analog of graphene. ${ }^{8-11}$ The germanene structure was first calculated in 2009 by Cahangirov et al. ${ }^{12}$ It has since been discussed in more than three hundred published papers. The proposed structure of germanene is a $2 \mathrm{D}$ hexagonal array of Ge atoms, and van der Waals stacking between the layers. Each layer has a graphene-like (HC) structure. However, unlike the ideally flat $\mathrm{sp}^{2}$ graphene structure, the energetically stable configuration of germanene is predicted to be low-buckled, with half of the atoms about $0.07 \mathrm{~nm}$ above the rest, as a result of some mixed $\mathrm{sp}^{2}-\mathrm{sp}^{3}$ hybridization (Figure 1). ${ }^{13}$ Germanene is a Dirac 2D material despite its buckled structure. ${ }^{14}$ Its bandgap is thus larger than graphene, about $24 \mathrm{meV}$, making germanene semimetallic. ${ }^{15-17}$ The Ge-Ge nearest neighbor distance is $0.24 \mathrm{~nm}$, resulting in $0.41 \mathrm{~nm}$ between 6 membered rings (Figure 1). ${ }^{18}$ A Raman shift of about $290 \mathrm{~cm}^{-1}$ has been predicted from ab initio studies. ${ }^{19-24}$

Germanene appears to be a unique material that does not exist in nature. However, due to the possibility of germanene being more facilely integrated into Si nanotechnology than graphene, ${ }^{16,25}$ development of synthetic methods for its formation are of interest. The silicon version of graphene, silicene, is generally unstable outside vacuum.

The deposition of germanene on metal surfaces in vacuum has been previously reported. On $\operatorname{Pt}(111)$, a $(\sqrt{ } 19 \times \sqrt{ } 19)$ R $23.4^{\circ}$ buckled structure has been synthesized in UHV by electron beam physical vapor deposition at room temperature, with subsequent annealing. According to STM images, and ab initio calculations, it was concluded that only one atom was higher in the six-member Ge atoms hexagon structure. ${ }^{26}$ In another report a $(\sqrt{ } 3 \times \sqrt{ } 3) \mathrm{R} 30^{\circ}$ germanene layer was formed on a $(\sqrt{ } 7 \times \sqrt{ } 7) \mathrm{R} 19.1^{\circ} \mathrm{Au}(111)$ supercell, deposited

\footnotetext{
*Electrochemical Society Student Member.

**Electrochemical Society Member.

***EElectrochemical Society Fellow.

${ }^{\mathrm{z} E}$ E-mail: stickney@uga.edu
}

by molecular beam epitaxy (MBE). The observed STM images displayed a honeycomb-like structure, though it was found to be nearly flat with interatomic distances of $0.255 \mathrm{~nm} .{ }^{27}$ Moreover, the same investigators reported formation of a few layers thick germanene structures with the same atomic distances $(0.256 \mathrm{~nm})$ and steps heights of about $0.32 \mathrm{~nm} .{ }^{28} \mathrm{~A}(3 \times 3)$ superstructure with similar interatomic distances was also observed on $\mathrm{Al}(111)$. The height of the germanene layer was found to be about $0.27 \mathrm{~nm} .{ }^{18}$ Formation of a germanene structure was also reported after evaporation of Pt onto Ge(110) and consequent flash annealing. ${ }^{29}$ Furthermore, multi-layered germanene (lonsdaleite germanium) was synthesized on a Si substrate by first depositing epitaxial $\mathrm{Si}_{0.65} \mathrm{Ge}_{0.35}$, and then exposure of the sample to a $\mathrm{N}_{2}$
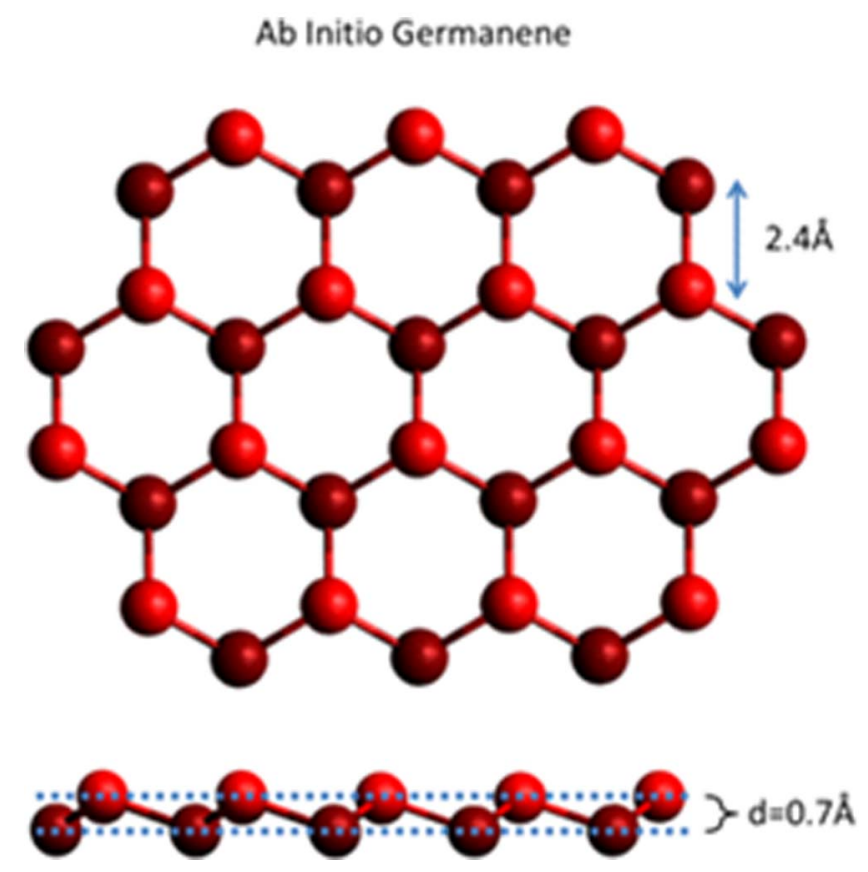

Figure 1. Proposed low-buckled germanene structure. One half of the Ge atoms are $0.07 \mathrm{~nm}$ higher than the other half. 
plasma and sequential annealing. ${ }^{30}$ D' Acapito et al. reported an X-ray absorption spectroscopy (XAS) study on the formation of Ge layers by MBE on an AlN buffered Ag substrates. First-principles calculations and the experimental data suggested the formation of germanene with atomic distances of $0.238 \mathrm{~nm} .{ }^{31}$ In addition, layered germanane, the hydrogenated form of germanene, was obtained through a topotactic deintercalation of $\mathrm{CaGe}_{2}{ }^{32}$

Due to its low hydrogen overpotential and the limited reactivity of Ge ions, electrodeposition studies of germanium were mostly performed in nonaqueous media. ${ }^{33-37}$ For example, Szekely has reported formation of Ge films by electrodeposition from a solution of germanium tetrachloride in propylene glycol with a plating speed of $0.001 \mathrm{in} . / 3 \mathrm{hr} .{ }^{34}$ Endres et al. have published a number of contributions concerning Ge electrodeposition studies from molten salts and ionic liquids, and was the first to use in situ STM for this system. ${ }^{38-42}$ Using germanium tetraiodide as a precursor resulted in a maximum deposit thickness of $20 \mathrm{~nm} .{ }^{38}$ Cyclic voltammetry studies by different researchers in nonaqueous media suggest that the deposition involved reduction of a $\mathrm{Ge}^{+4}$ species to a $\mathrm{Ge}^{+2}$ species, and subsequent reduction to $\mathrm{Ge}^{\circ} \cdot{ }^{36,41-46} \mathrm{Ge}$ electroplating has also been reported on semiconducting substrates such as $\mathrm{Si}^{47}$ There are some reports on the formation of thick Ge nanostructures, ${ }^{48-50}$ which showed that, depending on potential, Ge nanostructures can be grown from aqueous solution by dissolution into and saturation of a liquid $\mathrm{Hg}$ electrode. ${ }^{50}$ Ge nanowires were also formed by Al-Salman et al. by utilizing a solution of Ge in ionic liquids. ${ }^{44}$ Bartlett et al. have studied electrodeposition of $\mathrm{Ge}$ from various supercritical fluids containing $\mathrm{Ge}(\mathrm{II})$ or Ge(IV) compounds. ${ }^{46}$ They were able to obtain amorphous Ge films from $\mathrm{Ge}(\mathrm{IV})$ and $\mathrm{Ge}(\mathrm{II})$ precursors; however, films grown from $\mathrm{Ge}$ (II) compounds were heavily contaminated.

The authors have been investigating Ge electrodeposition from aqueous solutions onto $\mathrm{Au}$ and $\mathrm{Cu}$ substrates. ${ }^{51-53}$ The direct electrodeposition of $\mathrm{Ge}$ at a controlled potential from aqueous media appeared to be limited to 2-4 monolayers (ML), where a ML is defined here as one adsorbate atom per substrate surface atom. Still less Ge was observed depending on the potential, time and the $\mathrm{pH}$ used. To increase Ge coverages, an electrochemical ALD cycle (E-ALD) was developed, making use of surface limited reactions to grow $\mathrm{Ge}$ films an atomic layer at a time per cycle. That cycle was repeated to grow thicker deposits. At that time, Raman spectroscopy indicated formation of amorphous $\mathrm{Ge}$, from a broad peak at $270 \mathrm{~cm}^{-1} .53$

As mentioned above, germanene formation has been reported using gas-phase synthetic methods, requiring ultrahigh vacuum and elevated temperatures/annealing. The present report discusses investigations into the electrochemical formation of germanene layers on an $\mathrm{Au}$ electrode in $\mathrm{pH} 4.5$ aqueous solutions. Those deposits were studied at room temperature using EC-STM, cyclic voltammetry, micro-Raman spectroscopy and SXRD.

\section{Experimental}

EC-STM studies were performed using a Nanoscope III (Digital Instruments). All images were obtained in constant current mode. Electrochemical studies were performed using a three-electrode configuration, with an $\mathrm{Ag} / \mathrm{AgCl}$ ( $3 \mathrm{M} \mathrm{NaCl}$, BASI) reference, a platinum wire auxiliary, and an Au bead working electrode. Imaging was performed on $\mathrm{Au}(111)$ facets of a bead, prepared using a variation of the Clavilier method. ${ }^{54}$ Before each experiment, the Au bead was flame annealed, cooled down in a hydrogen atmosphere and quenched in ultrapure water $(>18.2 \mathrm{M} \Omega$ ) saturated with hydrogen, to ensure cleanliness and formation of large (111) terraces. The bead was quickly inserted into the EC-STM cell to avoid contaminations. 300-500 nm terraces were typically observed. STM tips were $0.25 \mathrm{~mm}$ tungsten rods, electrochemically etched in $1 \mathrm{M} \mathrm{KOH}$ solution, at $15 \mathrm{~V}$ ac, just prior to use. The tips were then coated with nail polish to reduce solution contact area, and thus faradaic reactions, leaving only the tip apex uncovered. The tip potential, $\mathrm{E}_{\mathrm{t}}$, was generally near $-150 \mathrm{mV}$ vs. Ag/AgCl. The STM was calibrated using HOPG. All glassware and parts were cleaned daily.
Aside from EC-STM studies, other electrochemical studies were performed using an automated electrochemical flow cell deposition system (Electrochemical ALD L.C., Athens, GA). The E-ALD hardware consisted of a flow cell, solenoid valves, solution reservoirs, pumps, relay box and potentiostat, all controlled using specialized "Sequencer 4" software. Solution reservoirs were purged with nitrogen, and valves and tubing were confined in a nitrogen atmosphere. The flow cell was also of a three-electrode configuration. The working electrodes (substrates) were $100 \mathrm{~nm}$ thick polycrystalline Au films, vapor deposited on a $5 \mathrm{~nm}$ thick Ti film on glass. The reference was an $\mathrm{Ag} / \mathrm{AgCl}$ ( $3 \mathrm{M} \mathrm{NaCl}$, BASI, West Lafayette, IN), and the auxiliary was an $\mathrm{Au}$ wire inlayed into the face of the flow cell, parallel to the substrate in order to simplify the current distribution. Each $\mathrm{Au}$ substrate was cleaned by cycling in $0.1 \mathrm{M}$ sulfuric acid before use

The SXRD measurements were performed at ID03 beamline at ESRF, France. The incident beam $(E=24 \mathrm{keV})$ was focused to $50 \times 300 \mu \mathrm{m}$ (vertical $\times$ horizontal) relative to the plane of the surface. The electrochemical setup consisted of a three-electrodePEKK flow cell, ${ }^{55}$ a PAR263 potentiostat and an automatic electrolyte distribution system. All glassware, teflon tubing and the PEEK cell were cleaned either in hot sulfuric acid or in diluted piranha solution prior to the experiment. The raw data were reduced to the rod profiles using BINoculars ${ }^{56}$ according to a previously described procedure. ${ }^{57}$ The fits were performed with the ROD code. ${ }^{58}$

All solutions were prepared with reagent grade chemicals and ultrapure water (18 M $\Omega$, obtained from a Millipore-Q system, fed with in-house DI water). Blank and germanium solutions contained $0.1 \mathrm{M}$ or $0.05 \mathrm{M} \mathrm{KClO}_{4}$ (Aldrich, $99.99 \%$ trace metals basis). The germanium solutions also contained $1 \mathrm{mM} \mathrm{GeO}_{2}$ (Alfa Aesar, 99.999\%, metals basis) in addition to the electrolyte. The solutions were $\mathrm{pH}$ 4.2 - 4.7, though no buffer was present. Raman spectra were obtained using a Renishaw InVia Raman microscope (Renishaw, Inc., Hoffman Estates, IL) with a $514 \mathrm{~nm}$ laser.

\section{Results and Discussion}

Figure 2 displays Ge deposition and stripping cyclic voltammetry $(\mathrm{CV})$ on polycrystalline $\mathrm{Au}$ on glass, from a $\mathrm{pH} 4.5$ germanium oxide $\left(\mathrm{GeO}_{2}\right)$ solution. The potential was scanned from $500 \mathrm{mV}$ to increasingly negative potential limits, and back. It suggests that $\mathrm{Ge}$ deposition starts near $-550 \mathrm{mV}$, and displays a peak at $-1250 \mathrm{mV}$.

The oxidation process appears totally irreversible, given that it all occurs positive of $-550 \mathrm{mV}$ (Figure 2 ), that the reduction charge is

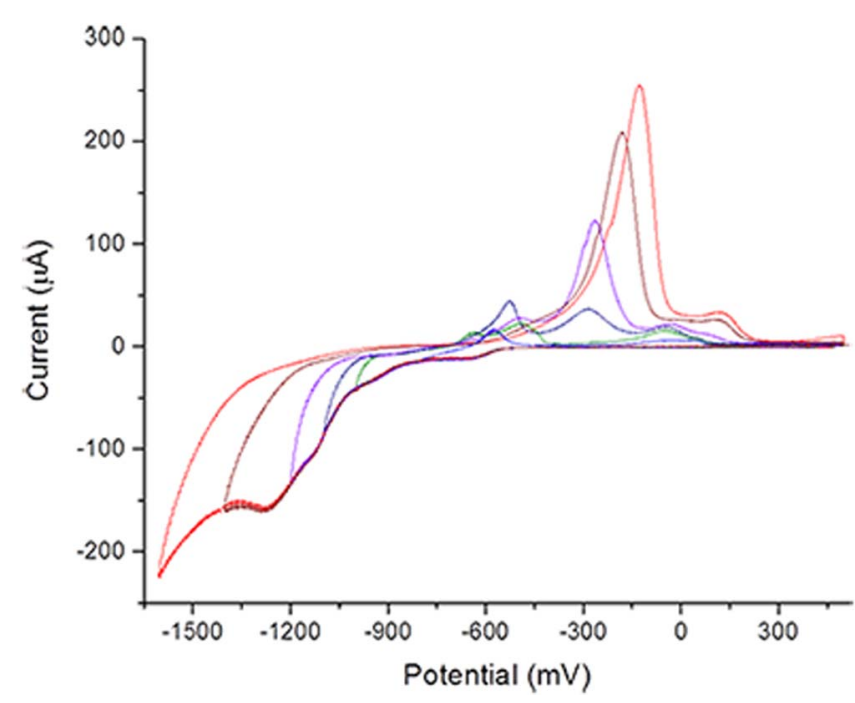

Figure 2. Window opening CVs of $0.5 \mathrm{mM} \mathrm{GeO}_{2}, 0.1 \mathrm{M} \mathrm{NaClO}_{4}(\mathrm{pH} 4.5)$ on a polycrystalline Au substrate from cathodic limits of $-700 \mathrm{mV}$ to -1600 $\mathrm{mV}$ while the anodic limit was kept to $500 \mathrm{mV}$ for each cycle. The scan rate used was $10 \mathrm{mV} / \mathrm{s}$. Area $=2 \mathrm{~cm}^{2}$. 


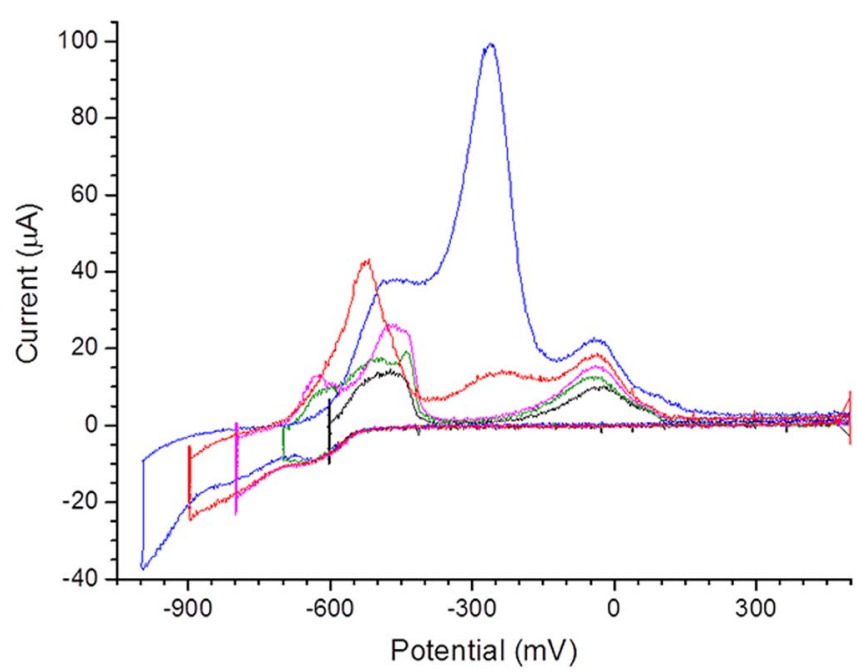

Figure 3. Window opening CVs of $0.5 \mathrm{mM} \mathrm{GeO}_{2}, 0.1 \mathrm{M} \mathrm{NaClO}_{4}(\mathrm{pH} 4.5$ ) on a polycrystalline Au substrate from cathodic limits of $-600 \mathrm{mV}$ to -1000 $\mathrm{mV}$, holding at these potentials for $700 \mathrm{sec}$, while the anodic limit was kept to $500 \mathrm{mV}$ for each cycle. The scan rate used was $10 \mathrm{mV} / \mathrm{s}$. Area $=2 \mathrm{~cm}^{2}$.

more than twice that for the oxidation suggests $\mathrm{H}_{2}$ formation during deposition. Some of the evident irreversibility results from changes in surface $\mathrm{pH}$. That is, as $\mathrm{H}_{2}$ forms, the $\mathrm{pH}$ at the surface increases, shifting Ge deposition negatively. For comparison, Figure 3 displays a series of CVs where the potential was held at the negative limit for $700 \mathrm{~s}$, helping to complete deposition and stabilize the surface $\mathrm{pH}$. Note that the purple Ge oxidative stripping curve in Figure 2, where the potential was reversed at $-1200 \mathrm{mV}$, was obtained in Figure 3 (blue) after holding at only $-1000 \mathrm{mV}$, for $700 \mathrm{~s}$.

Time dependent studies showed that small quantity of Ge can be deposited at potentials positive of $-550 \mathrm{mV}$, if the potential was held for a sufficient time (Figure 4). If the potential was not held at -500 $\mathrm{mV}$ (red CV), the oxidation scan gives no indication of Ge oxidation stripping. However, Ge oxidation is evident if the potential was held at the negative limit ( $200 \mathrm{~s}$ blue, $500 \mathrm{~s}$ black, and $700 \mathrm{~s}$ green). The

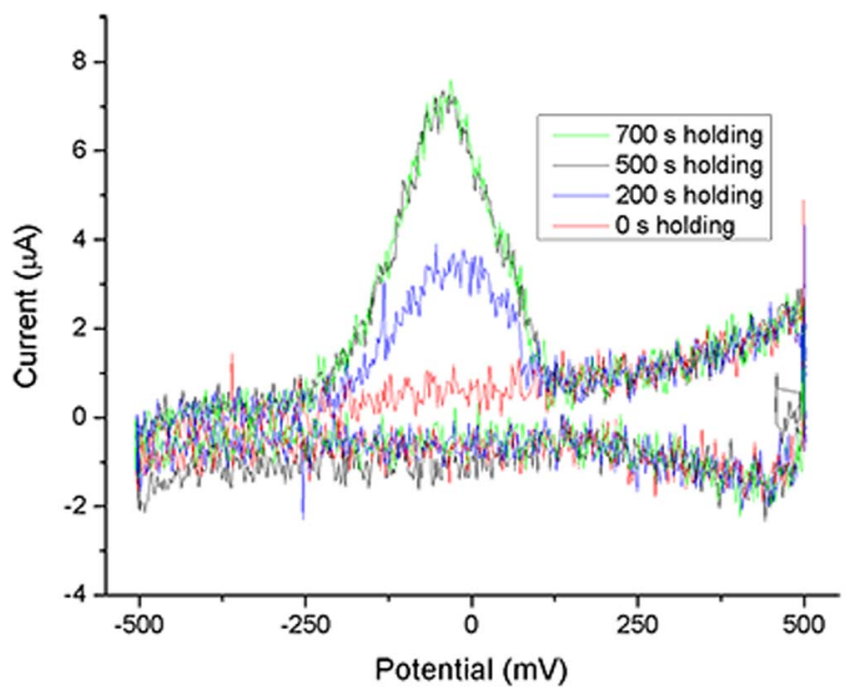

Figure 4. Oxidative stripping scans in $0.5 \mathrm{mM} \mathrm{GeO}_{2}, 0.1 \mathrm{M} \mathrm{NaClO}_{4}(\mathrm{pH} 4.7)$ on a polycrystalline Au substrate, after scanning to $-500 \mathrm{mV}$ from $500 \mathrm{mV}$ and holding the potential for $0,200,500$, or $700 \mathrm{~s}$. The scan was performed at $10 \mathrm{mV} / \mathrm{s}$, without solution flowing in the electrochemical flow cell. Area $=2$ $\mathrm{cm}^{2}$. Assuming a $4 \mathrm{e}^{-}$process, the oxidation peak at $-50 \mathrm{mV}$ indicated the presences of $0.062 \mathrm{ML}$ of Ge after $700 \mathrm{~s} \& 500 \mathrm{~s}$, and $0.036 \mathrm{ML}$ of Ge after $200 \mathrm{~s}$.

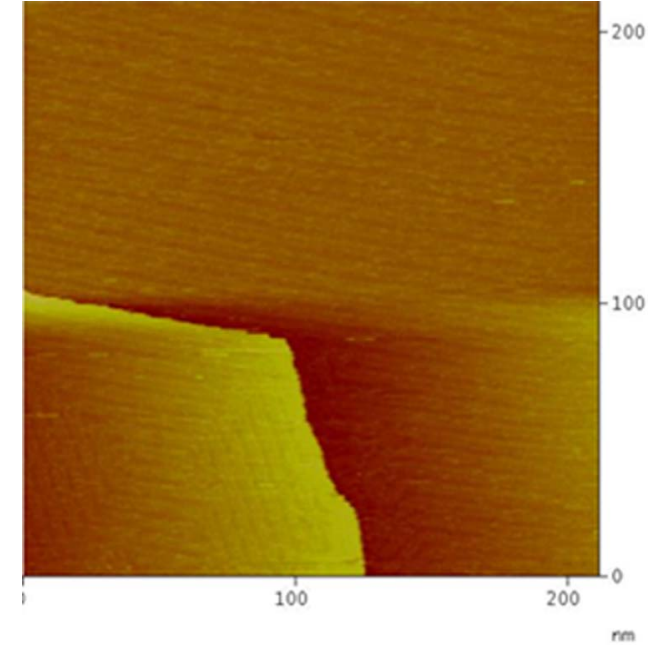

Figure 5. STM image of $\mathrm{Au}(111)$ herringbone $(\mathrm{HB})$ reconstruction in $1 \mathrm{mM}$ $\mathrm{GeO}_{2}$ and $0.1 \mathrm{M} \mathrm{KClO}_{4}(\mathrm{pH} 4.2$ ) before $\mathrm{Ge}$ deposition, at $-300 \mathrm{mV}$ vs. $\mathrm{Ag} / \mathrm{AgCl}$.

same profiles of black and green curves indicate a saturated $0.1 \mathrm{ML}$ Ge coverage at $-500 \mathrm{mV}$.

Figure 5 is an in situ EC-STM image of the $(\sqrt{ } 3 \times 22)$ herringbone (HB) $\mathrm{Au}(111)$ reconstruction, recorded at $-300 \mathrm{mV}$ in the $\mathrm{GeO}_{2}$ solution. The image appears equivalent to those previously observed for clean $\mathrm{Au}(111)$ surfaces in solution, in the absence of $\mathrm{Ge}$. On the other hand, at $-600 \mathrm{mV}$ the STM images in Figure 6 were obtained, where Ge coverage near $0.2 \mathrm{ML}$ was deposited while the surface reconstruction took place (Figure 3, black). The surface (Figure 6) displays a disordered reconstruction, with excessive elbows and rotations in the ridges, as well as pits at some of the elbows. It turns out that the potential for reconstruction of the $\mathrm{Au}(111)$ surface to the $\mathrm{HB}$ is about -300 $\mathrm{mV}$, while Ge appears to begin depositing near $-400 \mathrm{mV}$. The surface in Figure 6 resulted from a step to $-600 \mathrm{mV}$, so both the reconstruction and the beginning of Ge deposition took place together, possibly accounting for the disorder in the reconstruction. The defects in the surface, such as the holes (Figure $6 \mathrm{~b}$ ) and the wider areas between ridges, appear to be associated with Ge nucleation.

To check further the structure of the reconstruction after fast Ge deposition, SXRD measurements were performed on the reconstructed surface and after deposition of $\approx 0.1 \mathrm{ML}$. The HB reconstruction was first formed at $-500 \mathrm{mV}$ (Figure $7 \mathrm{a}$ ) and the subsequent measurements were taken at this potential. The reconstruction shows itself in the SXRD as set of four reconstruction rods positioned around the $(1,0)$ crystal truncation rod (CTR) as seen in the in-plane cut of reciprocal space (Figure 7a). ${ }^{59}$ The measurement of the specular $(0,0)$ CTR (Figure $7 \mathrm{c}$ ) confirms the low roughness of the surface and
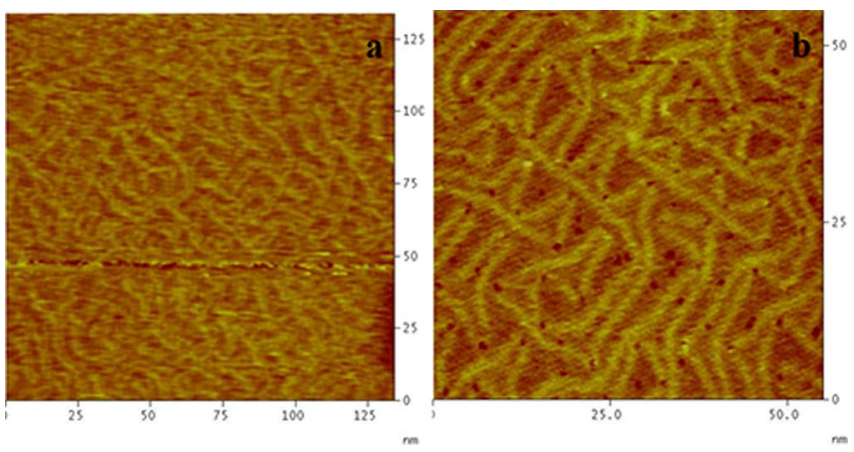

Figure 6. STM image of $\mathrm{Au}(111)$ in $1 \mathrm{mM} \mathrm{GeO}_{2}$ and $0.1 \mathrm{M} \mathrm{KClO}_{4}(\mathrm{pH}$ 4.2). Potential was stepped from $-300 \mathrm{mV}$ to $-600 \mathrm{mV}$ vs. $\mathrm{Ag} / \mathrm{AgCl}$ in $\mathrm{Ge}$ solution. HB lines restructured to a new pattern due to adsorption of $\mathrm{Ge}$ onto the surface. 

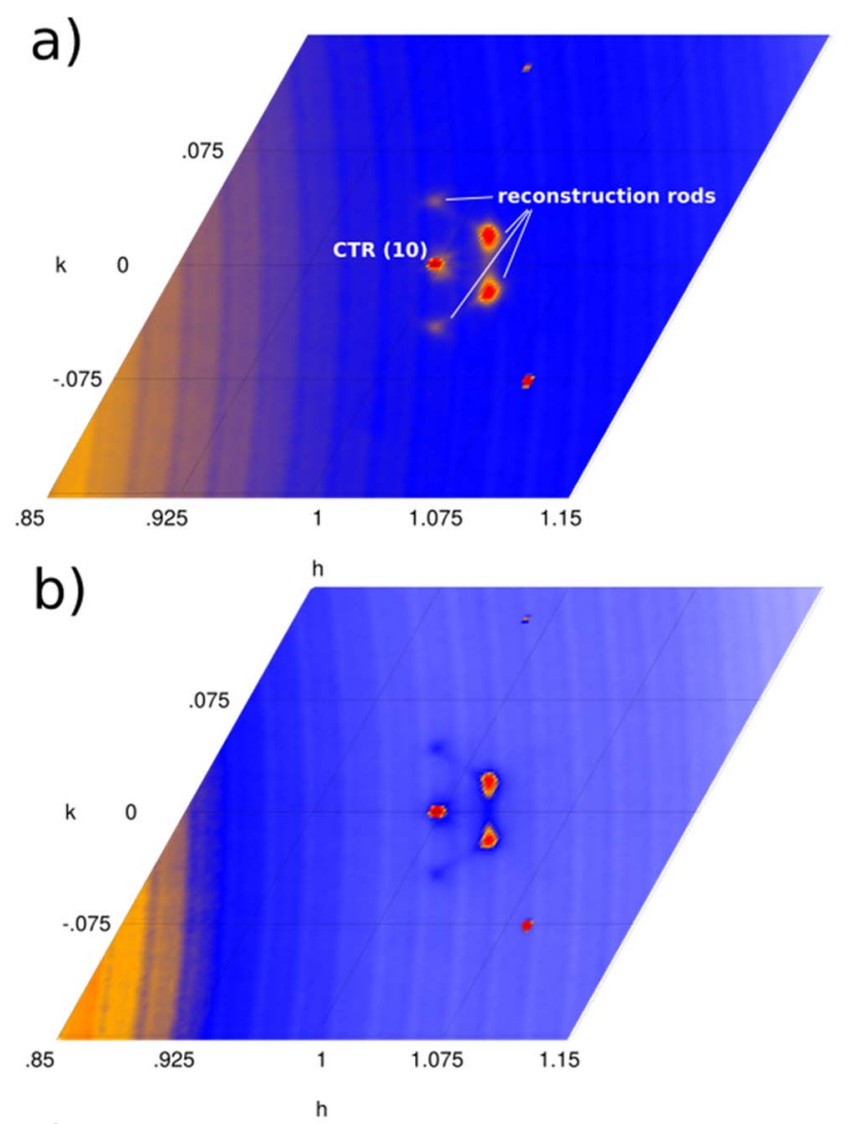

C)

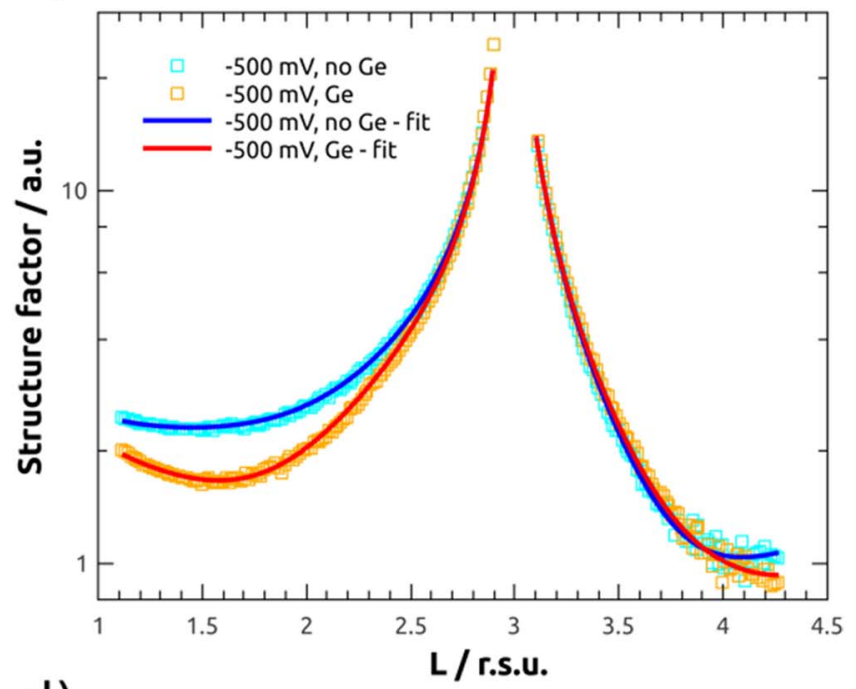

d)
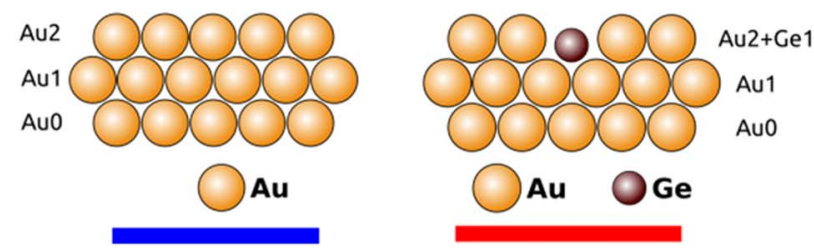

Figure 7. a) In-plane reciprocal space map of a $\mathrm{HB}$ reconstruction formed at $-500 \mathrm{mV}$ in $0.1 \mathrm{M} \mathrm{KClO}_{4}(\mathrm{pH} 4.2)$. b) In-plane reciprocal space map after deposition of about $0.1 \mathrm{ML}$ of $\mathrm{Ge}$ at $-500 \mathrm{mV}$ vs $\mathrm{Ag} / \mathrm{AgCl}$ in $1 \mathrm{mM} \mathrm{GeO}_{2}$ and $0.1 \mathrm{M} \mathrm{KClO}_{4}(\mathrm{pH} 4.2)$ showing maintained $\mathrm{HB}$ reconstruction. c) The profile of specular $(0,0)$ CTR before and after Ge deposition at $-500 \mathrm{mV}$. The solid lines correspond to the fit of the models shown in d).

\begin{tabular}{|c|c|c|}
\hline & $-500 \mathrm{mV}$, no Ge & $-500 \mathrm{mV}, \mathrm{Ge}$ \\
\hline $\mathrm{x}_{\mathrm{Au} 1}$ & $0.973 \pm 0.005$ & $0.97 \pm 0.02$ \\
\hline $\mathrm{x}_{\mathrm{Au} 2}$ & $1.03 \pm 0.01$ & $0.89 \pm 0.13$ \\
\hline $\mathrm{x}_{\mathrm{Ge} 1}$ & & $0.07 \pm 0.09$ \\
\hline $\mathrm{d}_{\mathrm{Au} 1-\mathrm{Au} 2}$ & $2.446 \pm 0.005$ & $2.41 \pm 0.02$ \\
\hline $\mathrm{d}_{\mathrm{Au} 1-\mathrm{Ge} 1}$ & & $1.2 \pm 2.6$ \\
\hline $\mathrm{DW}_{\mathrm{Au} 2}$ & $3.5 \pm 0.1$ & $2.2 \pm 0.8$ \\
\hline $\mathrm{DW}_{\mathrm{Au} 1}$ & $0.7 \pm 0.1$ & $0.8 \pm 0.1$ \\
\hline $\mathrm{DW}_{\mathrm{Ge} 1}$ & & $0 \pm 44$ \\
\hline Norm $x^{2}$ & 0.88 & 0.95 \\
\hline
\end{tabular}

generally good quality of the reconstruction. The important fitting parameters are shown in Table I. The top reconstructed layer is slightly relaxed outwards by $3.8 \%$ compared to the bulk interlayer distance, which correspond well with the value obtained previously with the same technique in vacuum (3.3\%). ${ }^{60}$ The fits also indicate $6 \%$ higher atomic density in the topmost layer compared to the bulk as expected for the compressed $\mathrm{HB}$ reconstruction.

While the potential was kept at $-500 \mathrm{mV}$, the electrolyte was changed to Ge containing electrolyte and the SXRD measurements were repeated. There are some noticeable differences: the minimum of the $(0,0)$ CTR shifts downward signaling Ge deposition and the inplane cut of the reciprocal space map shows that the reconstruction was maintained but the reconstruction rods appear to be weaker, supporting the STM observation of increased reconstruction disorder upon Ge deposition (Figure $7 b$ ). From the $(0,0)$ CTR fitting, we can determine the out-of-plane position of deposited Ge. Two models were proposed: i) $\mathrm{Ge}$ is incorporated in the reconstruction and ii) Ge is located on top of the reconstructed surface. In both cases the Ge coverage was similar, $\approx 0.07 \mathrm{ML}$ for the incorporated Ge incorporation and $\approx 0.08 \mathrm{ML}$ for the on-top Ge. However, better fit was obtained with the Ge incorporation model as judged from the normalized $\chi^{2}$ values (Table I). In this model the Au surface atoms belonging to the HB reconstruction are replaced by the adsorbed Ge (Figure 7d). The outward relaxation of the topmost $\mathrm{Au}$ atoms is slightly decreased while $\mathrm{Ge}$ atoms are positioned closer to the underlying Au layer as expected from the smaller size of Ge. Notably, the errors related to the Ge position, coverage and DW are large pointing to the high uncertainity in the location of the incorporated $\mathrm{Ge}$ atoms.

Similar behavior of the $\mathrm{HB}$ reconstruction during the deposition is reported in the literature. ${ }^{61-63}$ For example, Nahas et al. reported such behavior after deposition of $\mathrm{Pt}$ onto $\mathrm{Au}(111){ }^{62}$ They suggested that random intrusion of $\mathrm{Pt}$ atoms into the surface caused reconstruction modifications. In this case Ge atoms might incorporate at the elbows due to the edge dislocations present on the reconstructed surfaces, creating preferred binding spots. ${ }^{64,65}$ Sun et al. ${ }^{66}$ also observed similar behavior for the reconstruction after adsorption of a monolayer of perylene $(\mathrm{FePc})$.

The image in Figure 8a shows results from an experiment where the $\mathrm{HB}$ was first formed at $-300 \mathrm{mV}$ and then the potential was slowly shifted to $-400 \mathrm{mV}$, where small amount of Ge can be deposited (Figure 4). This can be compared to Figure 6, where the potential was stepped directly to $-600 \mathrm{mV}$. Figure 8 a shows 5-10 nm-long lines on the surface, which increased in number slowly while the potential was held at $-400 \mathrm{mV}$. The STM tip had some influence on the positions of the lines, and may have influenced line growth as well. Lines also grew on areas which had not been imaged, suggesting the STM tip was more a small perturbation than a method of line synthesis. Close inspection of sequential images indicated that the lines moved short distances and slowly grew in length, depending on the potential. It was also observed that the HB was present under the lines. Reconstructions can be lifted by adsorption. That the lines did not lift the HB suggests 


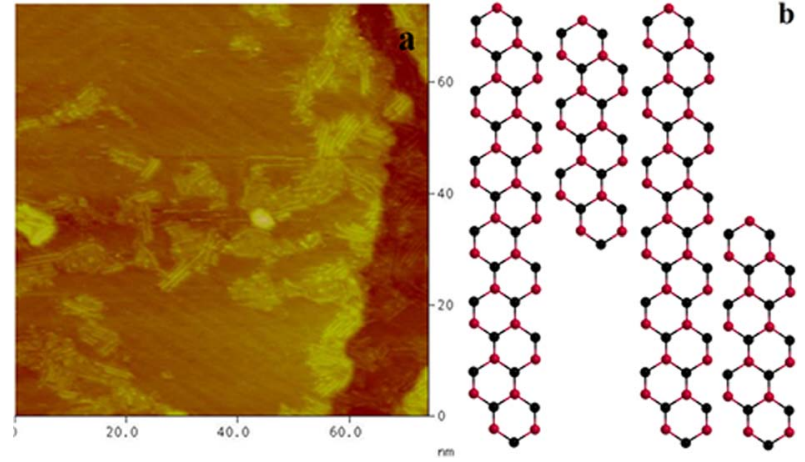

Figure 8. a) $\mathrm{STM}$ image of $\mathrm{Au}(111)$ in $1 \mathrm{mM} \mathrm{GeO}_{2}$ and $0.1 \mathrm{M} \mathrm{KClO}_{4}(\mathrm{pH}$ 4.2) at $-400 \mathrm{mV}$ vs. $\mathrm{Ag} / \mathrm{AgCl}$, showing germanene nanoribbons on the $\mathrm{Au}$ herringbone reconstruction. a) Formation of germanene nanoribbons at $-400 \mathrm{mV}$ lingering on top of the Au herringbone reconstruction. b) Proposed structures for germanene ribbons.

that the Ge interacted only weakly with the Au surface, as expected for van der Waals bonding.

Measurements of line heights varied between $0.1 \mathrm{~nm}$ and $0.06 \mathrm{~nm}$, with all measurements less than expected for an atomic layer. The lines might be atoms partially buried in the surface; however, they would be expected to strongly interfere with the reconstruction and not be expected to move significantly between images. If these thin lines are not strongly bound to the surface they should be influenced by imaging, which would account for their small movements and the difficulties determining their heights. Alternatively, the tunneling conditions, work function, may be very different between the Au HB and the lines. The inter-line spacing varied, but was generally near 0.8 $\mathrm{nm}$ to $1 \mathrm{~nm}$.

It is proposed here that the lines might be thin ribbons of germanene weakly adsorbed on top of the underlying Au(111) HB. Figure 8b is a diagram of a nanoribbon structure, based on dimensions from Figure $1 .{ }^{13,15,18}$ Related ribbon structures have been observed by other authors concerned with silicene, the silicon analog of graphene and germanene. ${ }^{67-74}$ The ribbons appear near step edges, both above and below, and near defects or disordered sites in the reconstruction. In addition to the gradual appearance of the ribbons in Figure 8a, a small number of $0.2 \mathrm{~nm}$ high islands were also observed, and appear to be single atom high $\mathrm{Au}(111)$ islands coated with the germanene ribbons. $\mathrm{The} \mathrm{Au}(111)$ islands probably result from atoms released by relaxation of the HB. ${ }^{75}$

Figure 9a shows an image of the disordered reconstructed surface at $-600 \mathrm{mV}$, which has a Ge coverage of $0.2 \mathrm{ML}$ as determined from coulometry. Figure $9 \mathrm{~b}$ shows a subsequent image where the potential was stepped from $-600 \mathrm{mV}$ to $-700 \mathrm{mV}$ half way up the scan, the bottom half was taken at $-600 \mathrm{mV}$ and the top half at -700 $\mathrm{mV}$ with the evident spray of particles. The particles appear to be similar in dimensions to the ribbons described above, each a few nm in size. Figure 9c was the subsequent down scan, in which most of the particles disappeared from the image. In addition, $8 \mathrm{c}$ displayed one atom deep horizontal pits of unknown origin across the image, though no conditions were changed between $8 \mathrm{~b}$ and $8 \mathrm{c}$. In Figure $9 \mathrm{~d}$ the scanned area was enlarged, from $170 \mathrm{~nm}$ to $300 \mathrm{~nm}$, and piles of the particles were evident on the left and right sides of the previous scanned area (Figures 9a-9c), suggesting they were not strongly bound to the surface and the tunneling conditions swept them from the field of view. These Ge nanoparticles were molecular in size, probably small pieces of the germanene, similar to the ribbons. They formed in Figure $9 \mathrm{~b}$ in a couple of seconds, after stepping to $-700 \mathrm{mV}$, possibly facilitated by $\mathrm{Ge}$ accumulated at or in the Au surface while holding at $-600 \mathrm{mV}$

The above experiments point to the fact that the preparation procedure plays a crucial role in the Ge deposition. Both on-top Ge (germanene) and incorporated $\mathrm{Ge}$ or both can be formed depending on the exact potential control sequence.
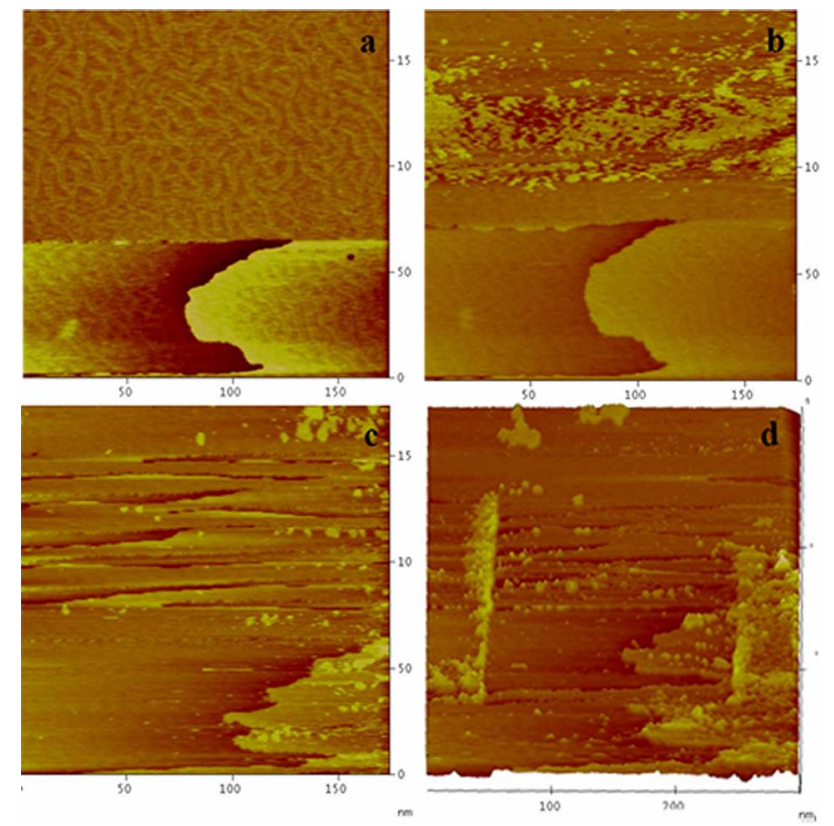

Figure 9. STM images of $\mathrm{Au}(111)$ in $1 \mathrm{mM} \mathrm{GeO}_{2}$ and $0.1 \mathrm{M} \mathrm{KClO}_{4}(\mathrm{pH}$ 4.2) taken $30 \mathrm{~s}$ apart. a) at $-600 \mathrm{mV}$ vs. $\mathrm{Ag} / \mathrm{AgCl}$; b) after the potential was stepped to $-700 \mathrm{mV}$; c) no change in conditions; d) no conditions were changed, however the scan area was expanded to show the piles of Ge.

After holding at $-800 \mathrm{mV}$, Figure 3 (pink), there are two oxidation features, at $-500 \mathrm{mV}$ and $-50 \mathrm{mV}$. The peak at $-50 \mathrm{mV}$ is nearly constant in each scan and accounts for stripping of the last $\mathrm{Ge}$ from the Au surface (about $0.2 \mathrm{ML}$ ) and it is referred here as oxidation of the underpotentially deposited Ge (UPD). ${ }^{38,76,77}$ UPD describes the electrodeposition of an atomic layer of one element on a second, the substrate, in a surface limited reaction. The other oxidation feature, between $-400 \mathrm{mV}$ and $-700 \mathrm{mV}$, is more easily oxidizable $\mathrm{Ge}$, arguably the result of oxidation of molecular scale germanene flakes from their edges. The low potential stripping peak was present in Figure 3 where the potential was held at -600 (black), -700 (green) or $-800 \mathrm{mV}$ (pink). Between the low potential and high potential stripping peak, however, is essentially no oxidative current passed. On the other hand, holding at $-900 \mathrm{mV}$ (red), or below (blue), an oxidation peak near $-300 \mathrm{mV}$ grows. The current in the new peak near $-300 \mathrm{mV}$ increased as the potential was held at more negative limits and for longer times, until the peak area saturated at 2 to 3 ML. Figure 2 displayed the same behavior, though the potential was not held, but simply reversed at increasingly negative limits. Note that in addition to the maximum current, potential increases with the more negative the potential limit, and the peak between $-700 \mathrm{mV}$ and -400 $\mathrm{mV}$ becomes suppressed as the $-300 \mathrm{mV}$ peak grows.

A $\mathrm{pH}$ dependence to the Ge coverage had previously been shown, with $\mathrm{pH} 9$ resulting in slightly more than $\mathrm{pH} 4.5 .^{52} \mathrm{Ge}$ coverages were determined using coulometry: integration of the currents recorded during oxidative Ge stripping (Figures 2 and 3), with the assumption here that the $\mathrm{GeO}_{2}$ in solution existed as $\mathrm{H}_{2} \mathrm{GeO}_{3}$ and underwent a $4 \mathrm{e}^{-}$reduction to $\mathrm{Ge}^{0}$ on the surface. XPS studies, by this group, indicated elemental Ge was present after deposition at the more negative potentials.

Figure 10 shows in situ STM images of an $\mathrm{Au}(111)$ facet on the $\mathrm{Au}$ bead electrode after scanning to $-1400 \mathrm{mV}$ and then back to -900 $\mathrm{mV}$, where the potential was held during imaging. At $-1400 \mathrm{mV}$, hydrogen evolution was extensive making imaging difficult, while at $-900 \mathrm{mV}$ the hydrogen evolution was minimized and the deposits remained stable enough to be imaged. Images in Figure 10 revealed the honeycomb nature of the Ge deposits, although the domains were small and only coherent in a nm scale. Based on the STM and coulometry from stripping of saturated Ge deposits, it was concluded that the 

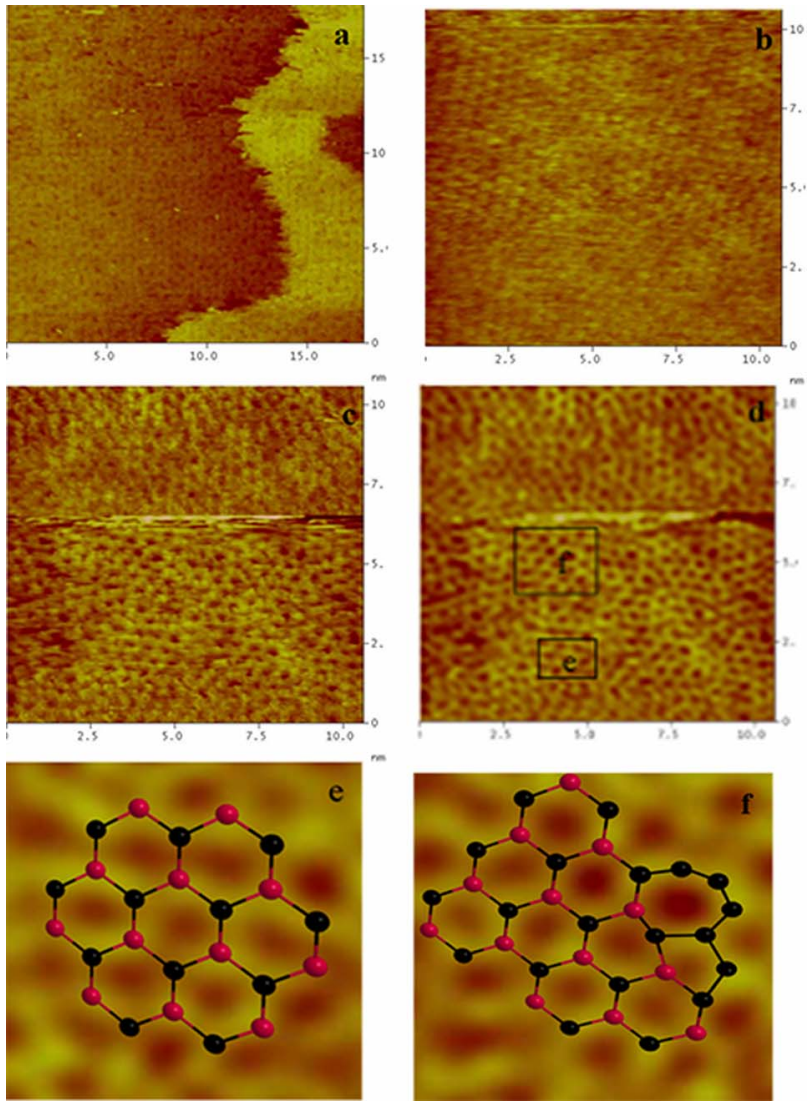

Figure 10. a-f are STM images of $\mathrm{Au}(111)$ in $1 \mathrm{mM} \mathrm{GeO}_{2}$ and $0.1 \mathrm{M} \mathrm{KClO}_{4}$ $(\mathrm{pH} 4.2)$ after the potential was scanned to $-1.4 \mathrm{~V}$ and then to $-900 \mathrm{mV}$ vs. $\mathrm{Ag} / \mathrm{AgCl}$. a) shows a strip of germanene on a layer of germanene. b) shows honeycomb structure, with $0.44 \pm 0.02 \mathrm{~nm}$ between the holes. c) shows nearly atomically resolved germanene. Image $d$ is FFT processed image $\mathrm{c}$ to enhance honeycomb structure. The boxes indicate where figures e and $\mathrm{f}$ were taken. e) Superposition of honeycomb structure drawing on FFT of germanene domain STM image. f) Superposition of germanene drawing, including 5- and 7-membered rings at domain wall, on FFT of germanene STM image.

Au surface was coated with the equivalent of two to three monolayers of Ge.

Figure 10a is an image of a strip of germanene on a germanene layer. The height of the strip was $0.35 \mathrm{~nm}$ above the underlying germanene, consistent with van der Waals bonding. The expected distance hole-to-hole in the honeycomb structure of germanene (Figure 1) is $0.41 \mathrm{~nm}$, while the distance measured on Figure 10b is $0.44 \pm 0.02$ $\mathrm{nm}$ which is close to the expected value. ${ }^{18}$

Figure $10 \mathrm{c}$ is a nearly atomically resolved image of a germanene deposit, showing the small coherent $\mathrm{HC}$ regions surrounded by different sized rings and rotated domains. Figure 10d is Figure 10c after a Fast Fourier Transform (FFT) filter, which removed any atomic resolution, accentuated the $\mathrm{HC}$ periodicities, the variation in hole size, the short coherence lengths and the angles between lines of holes in the HC domains. The short coherence lengths resulted from changes in bonding at domain walls, and are highlighted by variation in ring size (Figure 10e). Instead of only 6-atom rings, 5- or 7-atom rings were also present (Figure 10f), resulting in rotations of adjacent HC domains. The rectangles in Figure 10d indicate the regions where Figures $10 \mathrm{e}$ and $10 \mathrm{f}$ were taken. Studies of defects in graphene indicate that atom ejection lead to a recombination of the surrounding atoms to the rings with other than 6 atoms. ${ }^{78-81}$ The most common combinations were 5-7-7-5 and 5-8-5 rings, however, the average number of atoms per ring was still $6 .^{80}$ Figure $10 \mathrm{~d}$ reveal cluster defects of this type. A second type of defect results from change of the buckling structure. Ideally, the heights of the atoms alternate (Figure 1). How- ever, other configurations might also be feasible as they are expected to be only slightly higher in energy. For instance, neighboring atoms in a 6-membered ring might be both positioned higher, which would result in a small localized puckering in the low-buckle HC structure.

The authors suggest the defects in the germanene HC structure resulted from the growth mechanism. That is, it is believed that pieces of molecular germanene were nucleated first at some step edges or defects on the $\mathrm{Au}(111)$ substrate. Growth then continued at the edges until they made contact and grew together. The nanoparticles bonded when they encounter each other, but only in small domains of the $\mathrm{HC}$ structure. This growth does not appear to be reversible, under the conditions used, leading to the extensive amount of defects evident in Figure 10. The van der Waals nature of the germanene provides flexibility to the growth process, given the limited templating from lattice matching with the substrate.

The SXRD measurement confirms the formation of germanene layer (Figure 11 and Table II). The in-plane map of germanene layer
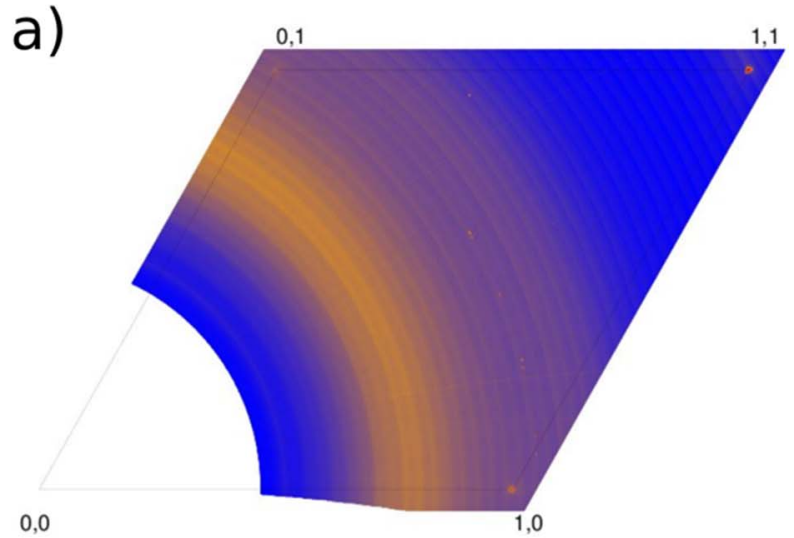

0,0

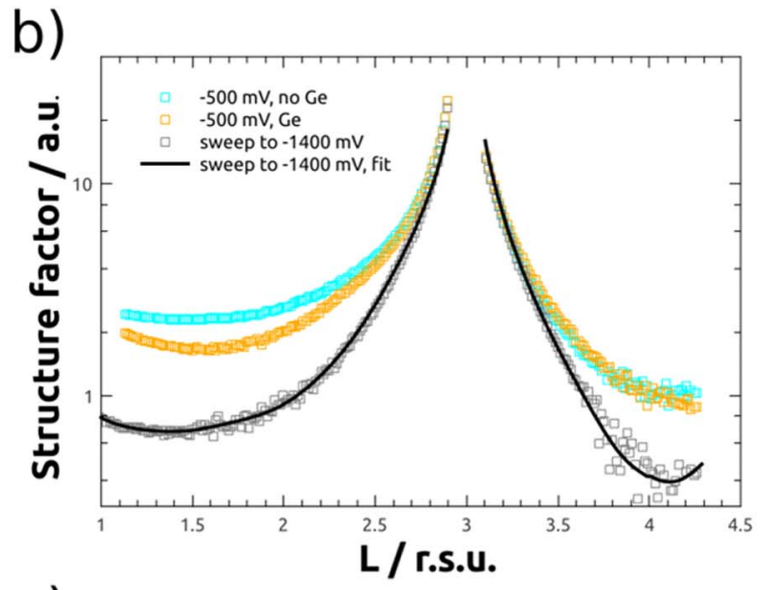

C)

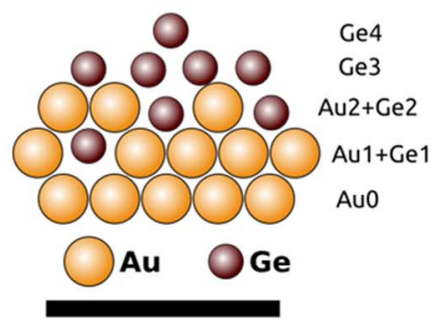

Figure 11. a) In-plane reciprocal space map of a Ge layer formed after the potential was swept to $-1400 \mathrm{mV}$ and back to $-900 \mathrm{mV} \mathrm{vs} \mathrm{Ag} / \mathrm{AgCl}$ in $1 \mathrm{mM}$ $\mathrm{GeO}_{2}$ and $0.1 \mathrm{M} \mathrm{KClO}_{4}(\mathrm{pH} 4.2)$. b) The profile of specular $(0,0) \mathrm{CTR}$ of the Ge layer deposited in a). The solid lines correspond to the fit of the models shown in c). 
Table II. Paramaters of the models used to fit the SXRD data showed in Figure 11b and 11c. $x$ is an occupancy parameter, $d$ is a distance between different surface planes as noted in Figure 11d, DW is a Debye-Waller parameter and norm $\chi^{2}$ is normalized chi squared.

After sweep to $-1400 \mathrm{mV}$ and back to $-900 \mathrm{mV}$

\begin{tabular}{|c|c|}
\hline $\mathrm{x}_{\mathrm{Au} 1}$ & $0.90 \pm 0.14$ \\
\hline $\mathrm{x}_{\mathrm{Au} 2}$ & $0.6 \pm 1$ \\
\hline $\mathrm{x}_{\mathrm{Ge} 1}$ & $0.06 \pm 0.1$ \\
\hline $\mathrm{x}_{\mathrm{Ge} 2}$ & $0.3 \pm 1$ \\
\hline $\mathrm{x}_{\mathrm{Ge} 3}$ & $0.39 \pm 0.06$ \\
\hline $\mathrm{x}_{\mathrm{Ge} 4}$ & $0.17 \pm 0.02$ \\
\hline $\mathrm{d}_{\mathrm{Au} 1-\mathrm{Au} 0}$ & $2.33 \pm 0.01$ \\
\hline $\mathrm{d}_{\mathrm{Au2}-\mathrm{Au} 1}$ & $2.4 \pm 0.2$ \\
\hline $\mathrm{d}_{\mathrm{Ge} 1-\mathrm{Au} 0}$ & $3 \pm 1$ \\
\hline $\mathrm{d}_{\mathrm{Ge} 2-\mathrm{Au} 1}$ & $3 \pm 1$ \\
\hline $\mathrm{d}_{\mathrm{Ge} 3-\mathrm{Au} 2}$ & $2.6 \pm 0.3$ \\
\hline $\mathrm{d}_{\mathrm{Ge} 4-\mathrm{Ge} 3}$ & $2.56 \pm 0.06$ \\
\hline $\mathrm{DW}_{\mathrm{Au} 1}$ & $2.8 \pm 0.1$ \\
\hline $\mathrm{DW}_{\mathrm{Au} 2}$ & $7 \pm 5$ \\
\hline $\mathrm{DW}_{\mathrm{Ge} 1}$ & $10 \pm 30$ \\
\hline $\mathrm{DW}_{\mathrm{Ge} 2}$ & $10 \pm 30$ \\
\hline $\mathrm{DW}_{\mathrm{Ge} 3}$ & $0 \pm 3$ \\
\hline $\mathrm{DW}_{\mathrm{Ge} 4}$ & $0 \pm 3$ \\
\hline Norm $\chi^{2}$ & 2.63 \\
\hline
\end{tabular}

deposited by the same potential sequence as in the STM measurements show no reconstruction of the underlying $\mathrm{Au}(111)$ substrate. Therefore the reconstruction have been lifted due to the Ge deposition. This is unexpected given the weak interaction of germanene with the substrate. To further probe the out-of-plane structure of the formed layer, we fitted the specular $(0,0)$ CTR (Figure $11 \mathrm{~b}$ ) with a model showed in Figure 11c). Three models with different Ge position were tried: i) Ge only on top of the substrate, ii) Ge alloyed within the substrate and (iii) combination of both above cases. The model where part of $\mathrm{Ge}$ is alloyed within the substrate and part resides gave the best fit as determined from the normalized $\chi^{2}$ and the F-test. This is not surprising as the incorporation of the deposited $\mathrm{Ge}$ atoms was observed at the onset of deposition as well. The parameters of the best fitting model are shown in Table II. In this model about $0.4 \mathrm{ML}$ of $\mathrm{Ge}$ is incorporated in the substrate in two layers. This coverage is, however, associated with a large error highlighting the uncertainty of the alloy structure. For the same reason all parameter errors associated with $\mathrm{Ge} 1$ and $\mathrm{Ge} 2$ are large. On top of this alloy are two germanene layers with occupancies $0.4 \mathrm{ML}$ and 0.2 ML. This is less then expected most due to the inhomogeneous nature of the Ge layer. The distance of the germanene layer from the substrate was determined to be $\approx 2.6$ $\AA$, lower then the distance determined from STM measurement. This measurement suggest that the layer is a mix of a germanene and more tightly bonded Ge structure. It is also likely that the local structure of the underlying alloy plays a role.

Thicker films of Ge were previously formed using a form of electrochemical atomic layer deposition (E-ALD). ${ }^{51-53}$ Raman spectra of the resulting deposits ${ }^{53}$ indicated the presences of amorphous Ge. However, one sample examined using micro-Raman spectroscopy, Figure 12, produced a number of spectra from a particular area which displayed a band near $290 \mathrm{~cm}^{-1}$. The peak close to $300 \mathrm{~cm}^{-1}$, Figure 12, was obtained from a $\mathrm{Ge}(100)$ wafer. According to published reports, a peak near $290 \mathrm{~cm}^{-1}$ corresponds to a "G-like" shift in the germanene layer. ${ }^{22,24}$ Moreover, Maldonado et al. studied Ge electrodeposition onto a surface enhanced Raman substrate (SERS-active $\mathrm{Au}$ ) on which the self-limited amount of Ge had been deposited. In that study a peak at $290 \mathrm{~cm}^{-1}$, at $-1.2 \mathrm{~V}$ in a $\mathrm{pH} 9.2 \mathrm{Ge}$ solution, was observed. Although germanene was not mentioned in that article, the results here suggest that it was formed. ${ }^{82}$

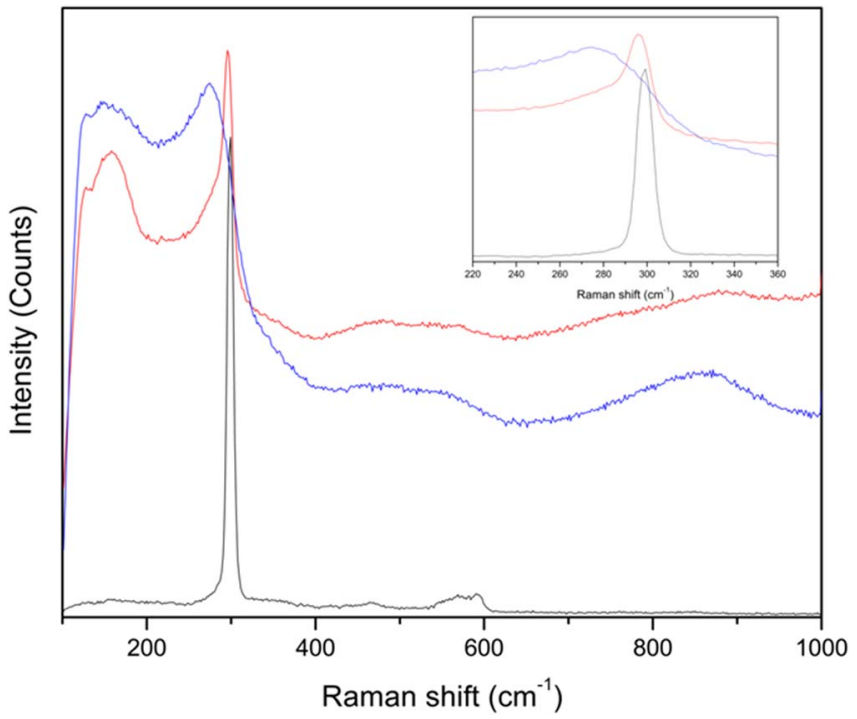

Figure 12. Raman spectra of Ge wafer (black) with a sharp peak near 300 $\mathrm{cm}^{-1}$, germanene spot (red) close to $290 \mathrm{~cm}^{-1}$, obtained from E-ALD Ge deposit, ${ }^{51}$ and amorphous Ge (blue) at $270 \mathrm{~cm}^{-1}$. The $290 \mathrm{~cm}^{-1}$ band was observed in a very limited area of the sample.

\section{Conclusions}

Electrochemical deposition of $\mathrm{Ge}$ onto $\mathrm{Au}$ and the formation of germanene in aqueous media have been discussed. Initial Ge deposits near $-400 \mathrm{mV}$ resulted in fractions of a Ge ML. At longer times at $-400 \mathrm{mV}$, ribbons of germanene were observed near step edges and defects in the $\mathrm{HB} \mathrm{Au}(111)$ surface. At more negative potentials, $-600 \mathrm{mV}$ or $-700 \mathrm{mV}$, extensive disordering of the $\mathrm{HB}$ was observed, and correlated with Ge incorporation on the Au surface. Below -700 $\mathrm{mV}$, germanene domains began to form between the patches of the HB. Those domains grew with time, slowly replacing the HB with germanene. At the same time, small $\mathrm{Au}$ islands appeared, probably the result of $\mathrm{Au}$ atoms released with the loss of the HB. The result was formation of a layer of germanene on the surface, which was followed by growth of large number of small islands of germanene, as a second layer of germanene was formed.

Depending on the potential-time program, STM and voltammetry suggest that nanoclusters of germanene were formed which were not strongly held to the surface, and were swept aside under the tunneling conditions. From voltammetry, the nanoparticles were easily oxidized during the positive scan. As larger sheets of germanene are formed, oxidation become less reversible and a new oxidation peak at around $-300 \mathrm{mV}$ began to grow in, shifting positive with increasing germanene coverage. It is proposed that this peak corresponds to a slower process, where the sheets oxidize at the edges, working in.

Images of the honeycomb-like structure of germanene obtained at potentials negative of $-1000 \mathrm{mV}$, where the hole-to-hole spacing was found to be $0.44 \pm 0.02 \mathrm{~nm}$. Although freestanding sheet of germanene is predicted to have an interatomic distance of $0.24 \mathrm{~nm}$, germanene grown on Au showed a Ge-Ge distance of $0.255-0.256 \mathrm{~nm} .{ }^{27,28}$ These numbers suggested a slight enlargement of the spacing between holes, from 0.41 to $0.44 \mathrm{~nm}$, which neatly coincides with the measurement obtained from this study. However, as can be seen from the images, the coherence lengths in domains of germanene were small. The domain walls appear to be composed of 5- or 7-atom rings, instead of the ideal 6 . The walls result in small rotations between adjacent domains. The SXRD measurements also confirmed formation of germanene layer after similar conditions to STM ones were used.

Micro-Raman spectroscopy of a thicker Ge deposit, previously made using an E-ALD cycle referred to as "Bait and Switch", was performed. A Raman peak near $290 \mathrm{~cm}^{-1}$ was observed, consistent with a predicted peak for germanene. 


\section{Acknowledgments}

Support from the National Science Foundation, DMR \#1410109, is gratefully acknowledged, in addition to support from the National Science Foundation grant CHE-1214152 and by the Gordon and Betty Moore Foundation (GBMF1225). The research was in part carried out through the Joint Center for Artificial Photosynthesis at the California Institute of Technology, a DOE Energy Innovation Hub, supported through the Office of Science of the U.S. Department of Energy under Award Number DE-SC0004993, which provided support for Y.-G.K. and M.P.S. to perform the EC-STM experiments. We thank Dr. Resta from the Synchrotron Soleil, L'Orme des Merisiers, for his contributions to this work.

\section{References}

1. A. Dimoulas, "Silicene and germanene: Silicon and germanium in the "flatland"," Microelectron Eng, 131, 68 (2015).

2. S. Balendhran, S. Walia, H. Nili, S. Sriram, and M. Bhaskaran, "Elemental Analogues of Graphene: Silicene, Germanene, Stanene, and Phosphorene," Small, 11(6), 640 (2015).

3. S. Kaneko, H. Tsuchiya, Y. Kamakura, N. Mori, and M. Ogawa, "Theoretical performance estimation of silicene, germanene, and graphene nanoribbon field-effect transistors under ballistic transport," Appl. Phys. Express, 7(3), 035102/1 (2014).

4. Y. Zhu, S. Murali, W. Cai, X. Li, J. W. Suk, J. R. Potts, and R. S. Ruoff, "Graphene and Graphene Oxide: Synthesis, Properties, and Applications," Adv. Mater. (Weinheim, Ger.), 22(35), 3906 (2010).

5. K. S. Novoselov, A. K. Geim, S. V. Morozov, D. Jiang, Y. Zhang, S. V. Dubonos, I. V. Grigorieva, and A. A. Firsov, "Electric Field Effect in Atomically Thin Carbon Films," Science (Washington, DC, U. S.), 306(5696), 666 (2004).

6. X. Li, Y. Zhu, W. Cai, M. Borysiak, B. Han, D. Chen, R. D. Piner, L. Colombo, and R. S. Ruoff, "Transfer of Large-Area Graphene Films for High-Performance Transparent Conductive Electrodes," Nano Lett, 9(12), 4359 (2009).

7. D. Li, M. B. Mueller, S. Gilje, R. B. Kaner, and G. G. Wallace, "Processable aqueous dispersions of graphene nanosheets," Nat. Nanotechnol., 3(2), 101 (2008).

8. S. Hu and X. Wang, "Ultrathin nanostructures: smaller size with new phenomena," Chem. Soc. Rev., 42(12), 5577 (2013).

9. B. Aufray, A. Kara, S. Vizzini, H. Oughaddou, C. Leandri, B. Ealet, and G. Le Lay, "Graphene-like silicon nanoribbons on $\operatorname{Ag}(110)$ : A possible formation of silicene," Applied Physics Letters, 96(18), 183102 (2010).

10. A. Kara, H. Enriquez, A. P. Seitsonen, L. C. L. Y. Voon, S. Vizzini, B. Aufray, and H. Oughaddou, "A review on silicene - New candidate for electronics," Surface Science Reports, 67(1), 1 (2012).

11. A. O'Hare, F. V. Kusmartsev, and K. I. Kugel, "A Stable "Flat" Form of TwoDimensional Crystals: Could Graphene, Silicene, Germanene Be Minigap Semiconductors?," Nano Letters, 12(2), 1045 (2012).

12. S. Cahangirov, M. Topsakal, E. Akturk, H. Sahin, and S. Ciraci, "Two- and OneDimensional Honeycomb Structures of Silicon and Germanium," Phys. Rev. Lett., 102(23), 236804/1 (2009).

13. F. Bechstedt, L. Matthes, P. Gori, and O. Pulci, "Infrared absorbance of silicene and germanene," Applied Physics Letters, 100(26), 261906 (2012)

14. J. Wang, S. Deng, Z. Liu, and Z. Liu, "The rare two-dimensional materials with Dirac cones," National Science Review, 2(1), 22 (2015).

15. Z. Ni, Q. Liu, K. Tang, J. Zheng, J. Zhou, R. Qin, Z. Gao, D. Yu, and J. Lu, "Tunable Bandgap in Silicene and Germanene," Nano Letters, 12(1), 113 (2012).

16. Q. Pang, C. L. Zhang, L. Li, Z. Q. Fu, X. M. Wei, and Y. L. Song, "Adsorption of alkali metal atoms on germanene: A first-principles study," Appl Surf Sci, 314, 15 (2014).

17. Y. Wang, Z. Ni, Q. Liu, R. Quhe, J. Zheng, M. Ye, D. Yu, J. Shi, J. Yang, J. Li, and J. Lu, "All-Metallic Vertical Transistors Based on Stacked Dirac Materials," Adv. Funct. Mater, 25(1), 68 (2015)

18. M. Derivaz, D. Dentel, R. Stephan, M.-C. Hanf, A. Mehdaoui, P. Sonnet, and C. Pirri, "Continuous germanene layer on $\mathrm{Al}(111)$," Nano Lett, 15(4), 2510 (2015).

19. M. Houssa, G. Pourtois, V. V. Afanas'ev, and A. Stesmans, "Electronic properties of two-dimensional hexagonal germanium," Applied Physics Letters, 96(8), 08211 (2010)

20. W. Wei, Y. Dai, B. Huang, and T. Jacob, "Many-body effects in silicene, silicane, germanene and germanane," Physical Chemistry Chemical Physics, 15(22), 8789 (2013).

21. D. Kaltsas and L. Tsetseris, "Stability and electronic properties of ultrathin films of silicon and germanium," Physical Chemistry Chemical Physics, 15(24), 9710 (2013).

22. E. Scalise, M. Houssa, G. Pourtois, B. Broek, V. Afanas'ev, and A. Stesmans, "Vibrational properties of silicene and germanene," Nano Res, 6(1), 19 (2013).

23. L. Matthes, O. Pulci, and F. Bechstedt, "Massive Dirac quasiparticles in the optical absorbance of graphene, silicene, germanene, and tinene," Journal of Physics-Condensed Matter, 25(39), 395305 (2013).

24. N. J. Roome and J. D. Carey, "Beyond Graphene: Stable Elemental Monolayers of Silicene and Germanene," ACS Appl. Mater. Interfaces, 6(10), 7743 (2014).

25. M. R. Tchalala, H. Enriquez, A. J. Mayne, A. Kara, G. Dujardin, M. A. Ali, and H. Oughaddou, "Iop Atomic structure of silicene nanoribbons on $\operatorname{Ag}(110)$," $3 \mathrm{rd}$ International Meeting on Silicene (Ims-3), 491 (2014).
26. L. Li, S.-z. Lu, J. Pan, Z. Qin, Y.-q. Wang, Y. Wang, G.-y. Cao, S. Du, and H.-J. Gao, "Buckled Germanene Formation on Pt(111)," Advanced Materials, 26(28), 4820 (2014).

27. M. E. Davila, L. Xian, S. Cahangirov, A. Rubio, and G. Le Lay, "Germanene: a novel two-dimensional germanium allotrope akin to graphene and silicene," New J. Phys., 16 (Sept.), 095002/1, 10 pp (2014).

28. M. E. Davila and G. Le Lay, "Few layer epitaxial germanene: a novel twodimensional Dirac material," Sci. Rep., 6, 20714 (2016).

29. P. Bampoulis, L. Zhang, A. Safaei, R. van Gastel, B. Poelsema, and H. J. W. Zandvliet, "Germanene termination of $\mathrm{Ge}_{2}$ Pt crystals on Ge(110)," J. Phys.: Condens. Matter, 26(44), 442001/1 (2014)

30. H.-S. Tsai, Y.-Z. Chen, H. Medina, T.-Y. Su, T.-S. Chou, Y.-H. Chen, Y.-L. Chueh, and J.-H. Liang, "Direct formation of large-scale multi-layered germanene on $\mathrm{Si}$ substrate," Phys. Chem. Chem. Phys., 17(33), 21389 (2015).

31. F. d'Acapito, S. Torrengo, E. Xenogiannopoulou, P. Tsipas, J. M. Velasco, D. Tsoutsou, and A. Dimoulas, "Evidence for Germanene growth on epitaxial hexagonal (h)-AlN on Ag(111)," Journal of Physics-Condensed Matter, 28(4) (2016).

32. E. Bianco, S. Butler, S. Jiang, O. D. Restrepo, W. Windl, and J. E. Goldberger, "Stability and Exfoliation of Germanane: A Germanium Graphane Analogue," ACS Nano, 7(5), 4414 (2013)

33. S. Jayakrishnan, M. Pushpavanam, and B. A. Shenoi, "Electrodeposition from organic solutions of metals that are difficult to deposit from aqueous solutions," Surf. Technol., 13(3), 225 (1981)

34. G. Szekely, "Electrodeposition of germanium," J. Electrochem. Soc., 98, 318 (1951).

35. A. Lahiri, S. Zein El Abedin, and F. Endres, "UV-Assisted Electrodeposition of Germanium from an Air- and Water-Stable Ionic Liquid," J. Phys. Chem. C, 116(33), 17739 (2012).

36. M. Wu, N. R. Brooks, S. Schaltin, K. Binnemans, and J. Fransaer, "Electrodeposition of germanium from the ionic liquid 1-butyl-1-methylpyrrolidinium dicyanamide," Phys. Chem. Chem. Phys., 15(14), 4955 (2013).

37. M. Wu, G. Vanhoutte, N. R. Brooks, K. Binnemans, and J. Fransaer, "Electrodeposition of germanium at elevated temperatures and pressures from ionic liquids," Phys. Chem. Chem. Phys., 17(18), 12080 (2015).

38. F. Endres and C. Schrodt, "In situ STM studies on germanium tetraiodide electroreduction on $\mathrm{Au}(111)$ in the room temperature molten salt 1-butyl-3methylimidazolium hexafluorophosphate," Phys. Chem. Chem. Phys., 2(24), 5517 (2000).

39. F. Endres, "Electrodeposition of a thin germanium film on gold from a room temperature ionic liquid," Phys. Chem. Chem. Phys., 3(15), 3165 (2001).

40. F. Endres, "Electrodeposition of nanosized germanium from $\mathrm{GeBr}_{4}$ and $\mathrm{GeCl}_{4}$ in an ionic liquid," Electrochem. Solid-State Lett., 5(3), C38 (2002).

41. F. Endres and S. Zein El Abedin, "Nanoscale electrodeposition of germanium on $\mathrm{Au}(111)$ from an ionic liquid: an in situ STM study of phase formation. Part II. Ge from $\mathrm{GeCl}_{4}$," Phys. Chem. Chem. Phys., 4(9), 1649 (2002).

42. F. Endres and S. Zein El Abedin, Nanoscale electrodeposition of germanium on $\mathrm{Au}(111)$ from an ionic liquid: an in situ STM study of phase formation. Part I. Ge from $\mathrm{GeBr}_{4}$," Phys. Chem. Chem. Phys., 4(9), 1640 (2002).

43. I. Mukhopadhyay and W. Freyland, "Thickness induced metal-nonmetal transition in ultrathin electrodeposited Ge films," Chem. Phys. Lett., 377(1,2), 223 (2003).

44. R. Al-Salman, J. Mallet, M. Molinari, P. Fricoteaux, F. Martineau, M. Troyon, Z. S. El Abedin, and F. Endres, "Template assisted electrodeposition of germanium and silicon nanowires in an ionic liquid," Phys. Chem. Chem. Phys., 10(41), 6233 (2008).

45. M. J. Jawad, M. R. Hashim, N. K. Ali, E. P. Corcoles, and M. E. Sharifabad, "An Alternative Method to Grow Ge Thin Films on Si by Electrochemical Deposition for Photonic Applications," J. Electrochem. Soc., 159(2), D124 (2012).

46. J. Ke, P. N. Bartlett, D. Cook, T. L. Easun, M. W. George, W. Levason, G. Reid, D. Smith, W. T. Su, and W. J. Zhang, "Electrodeposition of germanium from supercritical fluids," Physical Chemistry Chemical Physics, 14(4), 1517 (2012).

47. Q. Huang, S. W. Bedell, K. L. Saenger, M. Copel, H. Deligianni, and L. T. Romankiw, "Single-crystalline germanium thin films by electrodeposition and solid-phase epitaxy," Electrochemical and Solid State Letters, 10(11), D124 (2007).

48. E. Fahrenkrug, J. Gu, S. Jeon, P. A. Veneman, R. S. Goldman, and S. Maldonado, "Room-Temperature Epitaxial Electrodeposition of Single-Crystalline Germanium Nanowires at the Wafer Scale from an Aqueous Solution," Nano Lett, 14(2), 847 (2014).

49. N. K. Mahenderkar, Y.-C. Liu, J. A. Koza, and J. A. Switzer, "Electrodeposited germanium nanowires," ACS Nano, 8(9), 9524 (2014).

50. A. I. Carim, S. M. Collins, J. M. Foley, and S. Maldonado, "Benchtop Electrochemical Liquid-Liquid-Solid Growth of Nanostructured Crystalline Germanium," J. Am. Chem. Soc., 133(34), 13292 (2011).

51. X. Liang, N. Jayaraju, C. Thambidurai, Q. Zhang, and J. L. Stickney, "Controlled Electrochemical Formation of $\mathrm{Ge}_{\mathrm{x}} \mathrm{Sb}_{\mathrm{y}} \mathrm{Te}_{\mathrm{z}}$ using Atomic Layer Deposition (ALD)," Chem. Mater, 23(7), 1742 (2011)

52. X. Liang, Y.-G. Kim, D. K. Gebergziabiher, and J. L. Stickney, "Aqueous Electrodeposition of Ge Monolayers," Langmuir, 26(4), 2877 (2010).

53. X. Liang, Q. Zhang, M. D. Lay, and J. L. Stickney, "Growth of Ge Nanofilms Using Electrochemical Atomic Layer Deposition, with a "Bait and Switch" Surface-Limited Reaction," J. Am. Chem. Soc., 133(21), 8199 (2011).

54. J. Clavilier, R. Faure, G. Guinet, and R. Durand, "Preparation of monocrystalline platinum microelectrodes and electrochemical study of the plane surfaces cut in the direction of the $\{111\}$ and $\{110\}$ planes," J. Electroanal. Chem. Interfacial Electrochem, 107(1), 205 (1980).

55. M. L. Foresti, A. Pozzi, M. Innocenti, G. Pezzatini, F. Loglio, E. Salvietti, A. Giusti, F. D'Anca, R. Felici, and F. Borgatti, "In situ X-ray analysis under controlled potential 
conditions: An innovative setup and its application to the investigation of ultrathin films electrodeposited on $\operatorname{Ag}(111)$," Electrochimica Acta, 51(25), 5532 (2006).

56. S. Roobol, W. Onderwaater, J. Drnec, R. Felici, and J. Frenken, "BINoculars: data reduction and analysis software for two-dimensional detectors in surface X-ray diffraction," J Appl Crystallogr, 48, 1324 (2015).

57. J. Drnec, T. Zhou, S. Pintea, W. Onderwaater, E. Vlieg, G. Renaud, and R. Felici, "Integration techniques for surface X-ray diffraction data obtained with a twodimensional detector," J Appl Crystallogr, 47, 365 (2014).

58. E. Vlieg, "ROD: A program for surface X-ray crystallography," J Appl Crystallogr. 33, 401 (2000).

59. J. Wang, B. M. Ocko, A. J. Davenport, and H. S. Isaacs, "In situ X-Ray-Diffraction and X-Ray-Reflectivity Studies of the Au(111) Electrolyte Interface - Reconstruction and Anion Adsorption," Physical Review B, 46(16), 10321 (1992).

60. A. R. Sandy, S. G. J. Mochrie, D. M. Zehner, K. G. Huang, and D. Gibbs, "Structure and Phases of the Au(111) Surface - X-Ray-Scattering Measurements," Physical Review B, 43(6), 4667 (1991).

61. P. Allongue, L. Cagnon, C. Gomes, A. Gundel, and V. Costa, "Electrodeposition of $\mathrm{Co}$ and $\mathrm{Ni} / \mathrm{Au}(111)$ ultrathin layers. Part I: nucleation and growth mechanisms from in situ STM," Surface Science, 557(1-3), 41 (2004).

62. Y. Nahas, V. Repain, C. Chacon, Y. Girard, and S. Rousset, "Interplay between ordered growth and intermixing of Pt on patterned Au surfaces," Surf. Sci., 604(9-10), 829 (2010).

63. P. Campiglio, V. Repain, C. Chacon, O. Fruchart, J. Lagoute, Y. Girard, and S. Rousset, "Quasi unidimensional growth of Co nanostructures on a strained $\mathrm{Au}(111)$ surface," Surf. Sci., 605(13-14), 1165 (2011).

64. F. Besenbacher, J. V. Lauritsen, T. R. Linderoth, E. Laegsgaard, R. T. Vang, and S. Wendt, "Atomic-scale surface science phenomena studied by scanning tunneling microscopy," Surface Science, 603(10-12), 1315 (2009).

65. A. E. Baber, H. L. Tierney, and E. C. H. Sykes, "Atomic-Scale Geometry and Electronic Structure of Catalytically Important Pd/Au Alloys," ACS Nano, 4(3), 1637 (2010).

66. J. T. Sun, L. Gao, X. B. He, Z. H. Cheng, Z. T. Deng, X. Lin, H. Hu, S. X. Du, F. Liu, and H. J. Gao, "Surface reconstruction transition of metals induced by molecular adsorption," Phys. Rev. B: Condens. Matter Mater. Phys., 83(11), 115419/1 (2011).

67. C. Polop, C. Rojas, J. A. Martin-Gago, R. Fasel, J. Hayoz, D. Naumovic, and P. Aebi, "Structure of Si atomic chains grown on the Si/Cu(110) c $(2 \times 2)$ surface alloy," Phys. Rev. B: Condens. Matter Mater. Phys., 63(11), 115414/1 (2001).

68. P. De Padova, C. Quaresima, P. Perfetti, B. Olivieri, C. Leandri, B. Aufray, S. Vizzini, and G. Le Lay, "Growth of Straight, Atomically Perfect, Highly Metallic Silicon Nanowires with Chiral Asymmetry," Nano Lett, 8(1), 271 (2008).
69. A. Kara, C. Leandri, M. E. Davila, P. Padova, B. Ealet, H. Oughaddou, B. Aufray, and G. Lay, "Physics of Silicene Stripes," J. Supercond. Novel Magn., 22(3), 259 (2009).

70. G. Le Lay, B. Aufray, C. Leandri, H. Oughaddou, J. P. Biberian, P. De Padova, M. E. Davila, B. Ealet, and A. Kara, "Physics and chemistry of silicene nano-ribbons," Appl Surf Sci, 256(2), 524 (2009).

71. B. Aufray, A. Kara, S. Vizzini, H. Oughaddou, C. Leandri, B. Ealet, and G. Le Lay, "Graphene-like silicon nanoribbons on $\mathrm{Ag}(110)$. A possible formation of silicene,"Appl. Phys. Lett., 96(18), 183102/1 (2010).

72. P. De Padova, C. Quaresima, C. Ottaviani, P. M. Sheverdyaeva, P. Moras, C. Carbone, D. Topwal, B. Olivieri, A. Kara, H. Oughaddou, B. Aufray, and G. Le Lay, "Evidence of graphene-like electronic signature in silicene nanoribbons," Appl. Phys. Lett., 96(26), 261905/1-261905/3 (2010).

73. F. Ronci, S. Colonna, A. Cricenti, P. De Padova, C. Ottaviani, C. Quaresima, B. Aufray, and G. Le Lay, "Low temperature STM/STS study of silicon nanowires grown on the $\mathrm{Ag}(110)$ surface," Phys. Status Solidi C, 7(11-12), 2716 (2010).

74. P. De Padova, P. Perfetti, B. Olivieri, C. Quaresima, C. Ottaviani, and G. Le Lay, "1D graphene-like silicon systems: silicene nano-ribbons" J. Phys.: Condens. Matter, 24(22), 223001/1 (2012).

75. N. T. M. Hai, M. Van der Auweraer, K. Mullen, and S. De Feyter, "Self-Assembly of a Functionalized Alkylated Isophthalic Acid at the $\mathrm{Au}(111) /$ Electrolyte Interface: Structure and Dynamics," J Phys Chem C, 113(27), 11567 (2009).

76. F. Endres, "The electrodeposition of germanium from an ionic liquid: A mini-review on the nanoscale processes," Proc. - Electrochem. Soc., 2002-19(Molten Salts XIII), 677 (2002)

77. F. Endres and Z.S. El Abedin, "Nanoscale electrodeposition of germanium on $\mathrm{Au}(111)$ from an ionic liquid: an in situ STM study of phase formation - Part I. Ge from GeBr4," Physical Chemistry Chemical Physics, 4(9), 1640 (2002).

78. P. M. Ajayan and B. I. Yakobson, "Graphene. Pushing the boundaries," Nat. Mater. 10(6), 415 (2011).

79. P. Y. Huang, C. S. Ruiz-Vargas, A. M. van der Zande, W. S. Whitney, M. P. Levendorf, J. W. Kevek, S. Garg, J. S. Alden, C. J. Hustedt, Y. Zhu, J. Park, P. L. McEuen, and D. A. Muller, "Grains and grain boundaries in single-layer graphene atomic patchwork quilts," Nature (London, U. K.), 469(7330), 389 (2011).

80. P. T. Araujo, M. Terrones, and M. S. Dresselhaus, "Defects and impurities in graphene-like materials," Mater. Today (Oxford, U. K.), 15(3), 98 (2012).

81. L. Sun, F. Banhart, and J. Warner, "Two-dimensional materials under electron irradiation," MRS Bull, 40(1), 29 (2015).

82. A. I. Carim, J. Gu, and S. Maldonado, "Overlayer Surface-Enhanced Raman Spectroscopy for Studying the Electrodeposition and Interfacial Chemistry of Ultrathin Ge on a Nanostructured Support," ACS Nano, 5(3), 1818 (2011). 